8 Pollack S, Cunningham-Rundles C, Smithwick E M. High dose intravenous gammaglobulin for auto-immune neutropenia. $N$ Engl J Med 1982; 307: 253.

9 Catalano M A, Krick E N, De Heer D H, et al. Metabolism of autologous and homologous $\mathbf{I g G}$ in rheumatoid arthritis. J Clin Invest 1977; 60: 313-22.

\title{
Septic arthritis due to Bacteroides fragilis
}

SIR, We read with interest the report of Hart et al. ${ }^{1}$ of a case of Bacteroides fragilis septic arthritis of the wrist in a patient with rheumatoid arthritis (RA). They made the claim that this was probably the first case report of wrist joint involvement due to this organism. By coincidence we reported a similar case of septic polyarthritis due to Bacteroides fragilis in a patient with RA earlier in $1982 .{ }^{2}$ This patient had bacteroides sepsis in 9 joints including both wrists, and also responded well to metronidazole treatment.

A joint infection in a patient with RA should not only be considered when one joint suddenly flares up, but should also be borne in mind with a generalised flare-up, and anaerobic cultures should be done after joint aspirations as a routine investigation.

1640 Volkskas Centre,

Van der Walt Str.,

D. SCHORN

0002-Pretoria,

South Africa

\section{References}

1 Hart C A, Godfrey V M, Woodrow J C, Percival A. Septic arthritis due to Bacteroides fragilis in a wrist affected by rheumatoid arthritis. Ann Rheum Dis 1982; 41: 623-4.

2 Schorn D, Pretorius J A. Septic polyarthritis due to Bacteroides fragilis in a patient with rheumatoid arthritis. $S$ Afr Med J 1982; 62: $213-4$.

\section{Polymorphonuclear function in Behçet's syndrome}

SIR, The recent report by Fordham et al. ${ }^{1}$ has drawn attention to the role of polymorphonuclear leucocytes (PMN) in the pathogenesis of Behçet's disease. While the aetiology of Behçhet's disease remains unknown, immune complexinduced vasculitis with associated systemic inflammatory lesions are recognised key events in its pathogenesis. The occurrence of systemic inflammatory lesions has prompted studies of PMN function in Behçet's disease. Several investigators have found an increased PMN chemotactic response, ${ }^{1-5}$ although a reduced chemotactic response to inulin-activated serum and a normal chemotactic response to casein have also been described. ${ }^{6}$ Phagocytic and adherent properties of Behçet PMN are normal, ${ }^{1}$ while leucocyte oxygen consumption in the resting state and after stimulation by phagocytosis of Staphylococcus albus are diminished. ${ }^{3}$ Spontaneous nitroblue tetrazolium reduction is normal, whereas reduction after endotoxin stimulation is depressed. $^{3}$

These studies have prompted us to study the production of the toxic superoxide radical $\mathrm{O}_{2}^{-}$in response to stimulation with the chemotactic peptide $\mathrm{N}$-formylmethionylleucyl-phenylalanine (FMLP) in the PMN isolated from a 27-year-old female suffering from Behçet's disease of 8 years' duration. She had a present or past history of mouth and genital ulcerations, arthritis, and vasculitic skin lesions, thus fulfilling 3 major and one minor diagnostic criteria for Behçet's disease. ${ }^{7}$ At no time did she have eye or neurological involvement. Current treatment consisted of $15 \mathrm{mg}$ of prednisone and $20 \mathrm{mg}$ of piroxicam daily. For the assay of $\mathrm{O}_{2}$ produced by the activated $\mathrm{PMN}$, a ferricytochrome $\mathrm{C}$ reduction procedure was used. ${ }^{8}$ The production of $\mathrm{O}_{2}^{-}$was measured on 2 separate occasions comparing results with those obtained in 2 concurrently studied age and sexmatched healthy controls and with the normal ranges of the rate and quantities of $\mathrm{O}_{2}$ production earlier established in our laboratory for 33 normal controls. ${ }^{9}$ After prewarming the isolated PMN for 30 minutes 6-8 duplicate assays of $O_{2}^{-}$ production were performed during an approximate 3-hour period. Results are as follows:

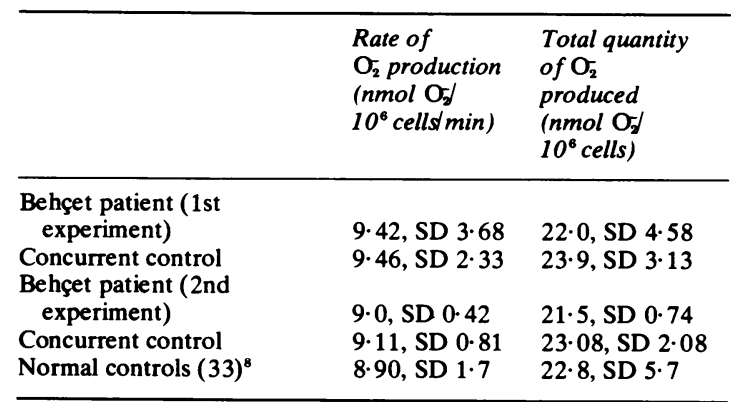

In this Behçet's patient both the rate as well as the total quantity of $\mathrm{O}_{2}^{-}$produced in response to stimulation with FMLP was clearly within normal limits when compared with both concurrent and previously tested controls. Abnormal production of toxic $\mathrm{O}_{2}^{-}$radical, a facet of PMN function, which to the best of our knowledge has not been studied before, may therefore not contribute to the generation of the systemic inflammatory lesions encountered in Behçet's disease.

Clinical Sciences Building,

CLAES FRIMAN

University of Alberta, PAUL DAVIS

Edmonton,

Alberta,

Canada T6G 2G3

\section{References}

1 Fordham J N, Davies P G, Kirk A, Currey H L F. Polymorphonuclear function in Behçet's syndrome. Ann Rheum Dis 1982; 41: 421-425.

2 Matsumara N, Mizushima $\mathrm{Y}$. Leucocyte movement and colchicine treatment in Behçet's disease. Lancet 1975; ii: 813.

3 Sobel J D, Haim S, Obedean V N, Meshulam T. Polymorphonuclear leucocyte function in Behçet's disease.J Clin Pathol 1977; 30: 250-3. 
4 James D W, Walker J R, Smith M J H. Abnormal polymorphonuclear leucocyte chemotaxis in Behçet's syndrome. Ann Rheum Dis 1979; 38: 219-21.

5 Takeuchi A, Kobayashi K, Mizushima Y. Mechanism of hyperchemotaxis of neutrophils from patients with Behçet's disease. In: Behçet's Disease Research Committee of Japan. Studies on Etiology, Treatment and Prevention of Behçet's Disease. Japan: Ministry of Welfare, 1978.

6 Abdulla Y H, Lehner T. The effect of immune complexes on chemotaxis in Behçet's syndrome and recurrent oral ulcers. In: Lehner T, Barnes C G, eds. Behçet's syndrome. London: Academic Press, 1979: 55-75.

7 Wright V A, Chamberlain M A. Behçet's syndrome. Bull Rheum Dis 1978-9; 29: 972-8.

8 Cohen H J, Chovaniec M E. Superoxide generation by digitonin-stimulated guinea pig granulocytes. J Clin Invest 1978; 401: 1081-7.

9 Chiu P, Davis P, Wong K, Dasgupta M. Superoxide production in neutrophils of patients with rheumatoid arthritis and Felty's syndrome.J Rheumatol in press.

\section{Parathyroid hormone}

Sir, We were astonished that Dunham et al. ${ }^{1}$ seemed to be ignorant of the work that our group has carried out over the past 10 years concerning the levels of parathyroid hormone (PTH) in haemochromatosis and idiopathic articular chondrocalcinosis.

As early as 1972 we studied the calcium and phosphorus balance in 44 patients with idiopathic haemochromatosis. We discovered an isolated increase in urinary phosphate clearance in nearly $30 \%$ of the patients studied. We proposed that idiopathic haemochromatosis may be accompanied by normocalcaemic hyperparathyroidism. ${ }^{2}$ This hypothesis was confirmed in 1974 by radioimmunoassay of the carboxyl fragment of PTH. In 7 out of 27 patients with haemochromatosis PTH levels were elevated. ${ }^{3}$ In 1975 , using the same radioimmunoassay, we compared PTH levels in 22 patients with haemochromatosis to 20 controls. Eleven of the patients with idiopathic haemochromatosis had PTH levels that were greater than the highest level found in the control group ( $<<0.01, W$ test). ${ }^{4}$ In 1979 we presented 38 observations on patients with idiopathic haemochromatosis and were able to show that a relationship existed between elevated PTH levels and the onset of clinical signs of arthropathy in younger patients (approximately 40 years old). In contrast PTH levels were significantly less increased ( $<<0.001, W$ test) in patients who were a decade older (about 50 years old) and who had roentgenographic evidence of articular chondrocalcinosis (Table 1). ${ }^{5}$

In 1981 we measured PTH levels in 69 patients with idiopathic articular chondrocalcinosis, who were classified

Table 1 Observations on 38 patients with haemochromatosis

\begin{tabular}{llll}
\hline Disorders & None & Clinical & X-ray \\
\hline Group & $(1)$ & $(2)$ & $(3)$ \\
Number & 11 & 6 & 21 \\
Age (years) & $42 \pm 6$ & $40 \pm 5$ & $53 \pm 9$ \\
PTH (ng/ml) & $0.82 \pm 0.57$ & $1.93 \pm 0.59$ & $0.76 \pm 0.55$ \\
\hline
\end{tabular}

according to whether the diagnosis was considered possible, probable, or certain. They were compared with 57 controls. This radioimmunoassay recognised a sequence between residues $34-84$ of the C-terminal fragment. Normocalcaemic hyperparathormonaemia was found in 15 out of 29 patients with 'possible chondrocalcinosis' (average age $39 \pm 11$ years), in 12 out of 16 patients with 'probable chondrocalcinosis' (average age $55 \pm 11$ years), and in 7 out of 24 patients with 'certain chondrocalcinosis' (average age $66 \pm 11$ years) ${ }^{6}$

We have established that in a large number of cases idiopathic haemochromatosis and idiopathic articular chondrocalcinosis share a common metabolic anomaly, normocalcaemic hyperparathormonaemia. These elevated PTH levels may play a key role in the development of osteoarticular changes in these diseases even if increased serum PTH is observed only during a given period, usually early in the evolution. We regret that Dunham et al. did not consider it necessary to refer to this body of work. None the less we are pleased that their results confirm both our findings and the hypotheses that we have proposed.

Clinique Thérapeutique,

Service de Médecine interne

Y. PAWLOTSKY G. CHALES J. COUTARD t de Rhumatologie,

Hôpital Sud,

J. MEADEB

BP 22129,

35022 Rennes Cedex,

France.

\section{References}

1 Dunham J, Bourke B E, Bitensky L, Chayen J, Loveridge N Scott J T. Circulating levels of biologically active parathyroid hormone in rheumatic diseases. Ann Rheum Dis 1982; 41: 569-73.

2 Pawlotsky, Y, Marcheteau M, Simon M, Ferrand B, Bourel M Observation anatomoclinique d'une hémochromatose avec hypoparathyroïdie et cancer du foie. Rev Rhum Mal Osteoartic 1972; 39: 259-70.

3 Pawlotsky Y, Roussey M, Hany Y, Simon M, Bourel M. Hyperparathormonémie dans l'hémochromatose idiopathique. Nouv Presse Med 1974; 3: 1757-8.

4 Pawlotsky, Y, Simon M, Hany Y, Brissot P, Bourel M. High plasma parathyroid hormone levels and osteoarticular changes in primary haemochromatosis. Scand J Rheumatol 1975; (suppl 8): 15-9.

5 Pawlotsky Y, Louboutin J Y, Hany Y, Roudier G, Brissot P, Bourel M. Hyperparathyroid origin of articular disorders in primary haemochromatosis. $\boldsymbol{R}$ (IXth European Congress of Rheumatology). September 1979: No. 215 (abstr).

6 Pawlotsky Y, Catheline M, Delbary M, et al. Hyperparathormonémie normocalcémique et chondrocalcinose articulaire. Etude de 69 patients comparés à 57 sujets témoins. Rev Rhum Mal Osteoartic 1981; 48: 799-806.

SIR, The essence of the work published by Pawlotsky and colleagues is that 'normocalcaemic hyperparathormonaemia' occurs commonly in 'idiopathic haemochromatosis and idiopathic articular chondrocalcinosis'. The whole point of our paper was the importance of measuring the biologically active hormone, since, as emphasised by McCarty et al.$^{1}$ there is considerable doubt as to what even the best radioimmunoassays of parathyroid hormone (PTH) are actually measuring. This 